\title{
USULAN PENGENDALIAN KUALITAS PRODUKSI BENANG CARDED DENGAN METODE SIX SIGMA
}

\author{
Abdul Manan, Firdanis Setyaning Handika, Ahmad Nalhadi \\ Program Studi Teknik Industri, Fakultas Teknik, Universitas Serang Raya \\ Email: Abdoel.manan02@gmail.com; firdanishandika@gmail.com; irqi02@gmail.com
}

\begin{abstract}
Abstrak - Sebuah Perusahaan benang berusaha untuk menghasilkan produk yang baik dan berkualitas, tetapi proses produksi yang dilakukan setiap harinya menimbulkan permasalahan terhadap produk cacat yang dihasilkan melebihi target yang sudah ditetapkan sebesar $5 \%$. Penelitian ini menggunakan metode Six Sigma tetapi hanya sampai tahap improve. Penelitian bertujuan untuk menentukan nilai DPMO dan level sigma di bagian proses produksi spinning, mengetahui faktor faktor apa saja yang menyebabkan cacat dan merekomendasikan cara atau parameter baru untuk menurunkan cacat tersebut. Berdasarkan hasil penelitian diketahui bahwa nilai DPMO pada jenis benang $C D$ di bagian spinning sebesar 17.130 dan level sigma 3,6. Level sigma tersebut sudah melebihi rata-rata industri Indonesia, tetapi persentase cacat sebesar 8,7\%, cacat tersebut melebihi target yang telah ditetapkan sebesar 5\%. Appron rusak dan kotor, terompet tersumbat, serta selang pelumas bocor, merupakan faktor yang mengakibatkan cacat. Selanjutnya, dengan Failure Mode Effect Analysis (FMEA) diperoleh nilai Risk Priority Number (RPN) tertinggi pada cacat kusut yaitu appron rusak (140) dan terompet tersumbat (120), sedangkan nilai RPN tertinggi pada cacat kotor yaitu appron kotor (150) dan selang pelumas bocor (120).
\end{abstract}

Kata kunci: FMEA; Pengendalian Kualitas; Six Sigma

Abstract -- A yarn company strives to produce good and quality products, but the production process that is carried out by each person will produce products targeted at a target that has been set at $5 \%$. This study uses the Six Sigma method but only until the improvement stage. The research is to determine the DPMO value and sigma level in the spinning production process, to know what factors cause defects and new parameters to reduce the defect. Based on the results of the study that the $D P M O$ on the type of CD thread in the spinning section is 17,130 and the sigma level is 3,6. The level of sigma that has dominated the Indonesian industry average, but has a defect of $8.7 \%$, the target set at 5\%. Damaged and dirty apron, clogged trumpet, and leaky hose are factors that plan defects. Furthermore, with Failure Mode Effect Analysis (FMEA), the highest value of Risk Priority Number (RPN) in tangled defects is that the apron is damaged (140) and clogged trumpet (120), while the highest RPN value is gross dirty, i.e., dirty apron (150) and hose leaking lubricant (120).

Keywords: FMEA; Quality Control; Six Sigma

\section{PENDAHULUAN}

Perbaikan kualitas produksi dengan menekan jumlah produk cacat merupakan salah satu langkah penting untuk mencapai tujuan perusahaan, karena biaya tersembunyi yang muncul dari adanya produk cacat tersebut memiliki dampak yang cukup besar pada perusahaan.

Salah satu pabrik tekstil dengan bahan baku yang digunakan yaitu kapas dan hasil produksi yang dihasilkan perusahaan adalah benang tenun dengan jenis benang TC, CD, CVC dan TCD, kapasitas produksi benang yang dihasilkan berkisar antara 2.300 ball ( 1 ball = $181,44 \mathrm{~kg}$ ) perbulan. Perusahaan selalu berusaha untuk menghasilkan produk yang baik dan berkualitas, akan tetapi proses produksi yang dilakukan setiap harinya menimbulkan permasalahan terhadap produk jenis benang yang diproduksi. Pada saat melakukan penelitian diketahui bahwa jenis benang Carded (CD) memiliki jumlah cacat terbesar yaitu 438,27 ball. Dalam satu bulan produksi perusahaan menetapkan target sebesar $5 \%$ untuk produk cacat, akan tetapi target tersebut sulit untuk dicapai karena ada nya produk cacat yang melebihi target. Maka dari itu untuk menurunkan produk cacat pada bagian spinning upaya perbaikan yang akan dilakukan adalah dengan menggunakan Six Sigma. 
Six Sigma merupakan kegiatan yang dilakukan oleh semua anggota perusahaan yang menjadi budaya dan sesuai dengan visi dan misi perusahaan. Tujuannya Six Sigma adalah untuk meningkatkan sistem manajemen perusahaan dalam rangka meningkatkan kepercayaan pelanggan. mempunyai tujuan untuk memperbaiki sistem manajemen perusahaan atau instansi (Supriyadi, Ramayanti, \& Roberto, 2017). Strategi penerapan six sigma disebut sebagai The Six Sigma Breakthrough Strategy. Strategi ini merupakan metode sistematis yang menggunakan pengumpulan data dan analisis statistik untuk menentukan sumber - sumber variasi dan cara-cara untuk menghilangkannya (Zahara, 2014).

Six Sigma adalah konsep statistik yang mengukur suatu proses yang berkaitan dengan cacat pada level enam (six) sigma yaitu hanya ada 3,4 cacat dari sejuta peluang. Six sigma juga merupakan falsafah manajemen yang berfokus untuk menghapus cacat dengan cara menekankan pemahaman, pengukuran, dan perbaikan proses (Sirine \& Kurniawati, 2017).

Penelitian-penelitian pengendalian kualitas pada perusahaan benang telah sukses diimplemantasikan (Das, Roy, \& Antony, 2007; Gupta \& Bharti, 2013; Hussain, Jamshaid, \& Sohail, 2014). Penelitian ini mengadopsi implementasi Six Sigma di dunia industri textile. Penelitian ini bertujuan menentukan nilai DPMO dan level sigma dibagian proses produksi spinning, mengetahui faktor - faktor apa saja yang menyebabkan cacat dan merekomendasikan cara atau parameter baru untuk menurunkan cacat tersebut. Hasil penelitian diharapkan mampu menurunkan cacat yang terjadi pada produksi benang.

\section{METODE PENELITIAN}

Pnelitian ini menggunakan aplikasi Six sigma dalam memecahkan permasalahan pada proses produksi benang. Tahapan Six Sigma yang dilakukan adalah dengan menggunakan tahapan DMAIC (Define, Measure, Analyze, Improve, Control). Data yang digunakan dalam penelitian ini adalah data produksi dan data cacat yang terjadi.

\section{Define}

Merupakan langkah operasional pertama dalam program peningkatan kualitas Six Sigma. Dalam tahapan pertama ini, dilakukan pernyataan masalah, tahap kedua menjelaskan tujuan serta tahap ketiga membuat diagram SIPOC.

Diagram SIPOC merupakan suatu diagram yang biasa digunakan dalam tahap define untuk memberi gambaran secara umum terhadap proses yang ada saat ini. SIPOC yang merupakan akronim dari lima elemen utama dalam sistem kualitas, yaitu Supplier Input Process Output Customer (Gaspersz, 2002).

\section{Measure}

Merupakan langkah operasional kedua dalam program peningkatan kualitas Six Sigma (Gaspersz, 2002).

1. Menentukan Karakteristik Kualitas (CTQ)

Tahapan pengevaluasian sistem pengukuran karakteristik (CTQ) dan menentukan nilai six sigma. Penentuan karakteristik CTQ dominan untuk dijadikan prioritas dalam penyelesaian masalah.

2. Menentukan Defect Per Milion Opportunity (DPMO) dan level sigma.

$$
\mathrm{DPMO}=\frac{\text { Jumlah cacat }}{\text { Jumlah produksi X CTQ }} \times 1.000 .000
$$

Level Sigma $=$ Normsinv $\left(\frac{10^{6}-D P M O}{10^{6}}\right)+1.5$

3. Analisis Peta $P$

a. Menghitung Persentasi Kerusakan

$$
p=\frac{n p}{n}
$$

b. Menghitung garis pusat/ Central line (CL)

$$
\mathrm{CL}=\bar{p}=\frac{\sum n p}{\sum n}
$$

c. Menghitung batas kendali atas atau Upper Control Limit (UCL)

$$
\mathrm{UCL}=\bar{p}+3 \sqrt{\frac{\bar{p}(1-\bar{p})}{n}}
$$

d. Menghitung batas kendali bawah atau Lower Control Limit (LCL)

$$
\mathrm{LCL}=\bar{p}-3 \sqrt{\frac{\bar{p}(1-\bar{p})}{n}}
$$

\section{Analyze}

\section{Analisis Diagram Pareto}

Diagram pareto adalah diagram yang digunakan untuk mengidentifikasi, mengurutkan dan bekerja untuk menyisihkan kerusakan produk secara permanen. Dengan diagram ini, maka dapat diketahui jenis cacat yang paling dominan pada hasil produksi selama bulan April 2017 - Maret 2018.

2. Analisis penyebab masalah dengan diagram sebab-akibat.

3. Analisis failure Mode and Effect Analysis (FMEA)

Failure Mode and Effect Analysis (FMEA) digunakan untuk mengidentifikasi sumbersumber dan akar penyebab dari suatu masalah kualitas. Pembuatan tabel FMEA dimulai dari penentuan jenis kegagalan, efek dari kegagalan tersebut, penyebab dari kegagalan yang terjadi, kontrol yang akan dilakukan, dan upaya 
penanggulangannya. Nilai Severity, Occurance dan Detection diperoleh dari hasil branstorming dengan Production Manager dan Inspection Manager. Selanjutnya dilakukan perhitungan nilai RPN yang diperoleh dari hasil perkalian nilai Severity, Occurance dan Detection.

\section{Improve}

Melakukan perencanaan usulan perbaikan untuk mencegah terjadinya cacat serta agar mendapatkan hasil perbaikan yang sesuai dan mencapai tujuan yang telah ditetapkan. Rencana perbaikan dibuat berdasarkan nilai RPN tertinggi. Dengan menggunakan $5 \mathrm{~W}+1 \mathrm{H}$.

\section{HASIL DAN PEMBAHASAN}

Pembahasan penelitian berdasarkan data history selama bulan April 2017 - Maret 2018. Data tersebut diolah dengan menggunakan tahapan Six Sigma.

\section{Define}

Pada tahap ini dilakukan identifikasi terhadap produk yang akan diteliti dalam rangka peningkatan kualitas produk. Berdasarkan hasil yang diperoleh, diketahui bahwa produk yang dihasilkan benang carded masih banyak mengalami kecacatan sehingga produk tersebut menjadi perhatian dalam penelitian ini.

terdapat jumlah produk cacat yang masih terjadi setiap pabrik berproduksi pada bagian spinning. Cacat tersebut yaitu benang kusut, benang kotor, benang putus, benang tebal dan benang tipis. Adapun persentase cacat produk benang dapat dilihat pada tabel 1 .

Tabel 1. Data cacat jenis benang CD pada bagian spinning

\begin{tabular}{cc}
\hline Jumlah Cacat & Persentase \\
\hline 42.248 & $53,1 \%$ \\
20.350 & $25,6 \%$ \\
8.969 & $11,3 \%$ \\
4.349 & $5,5 \%$ \\
3.603 & $4,5 \%$ \\
\hline
\end{tabular}

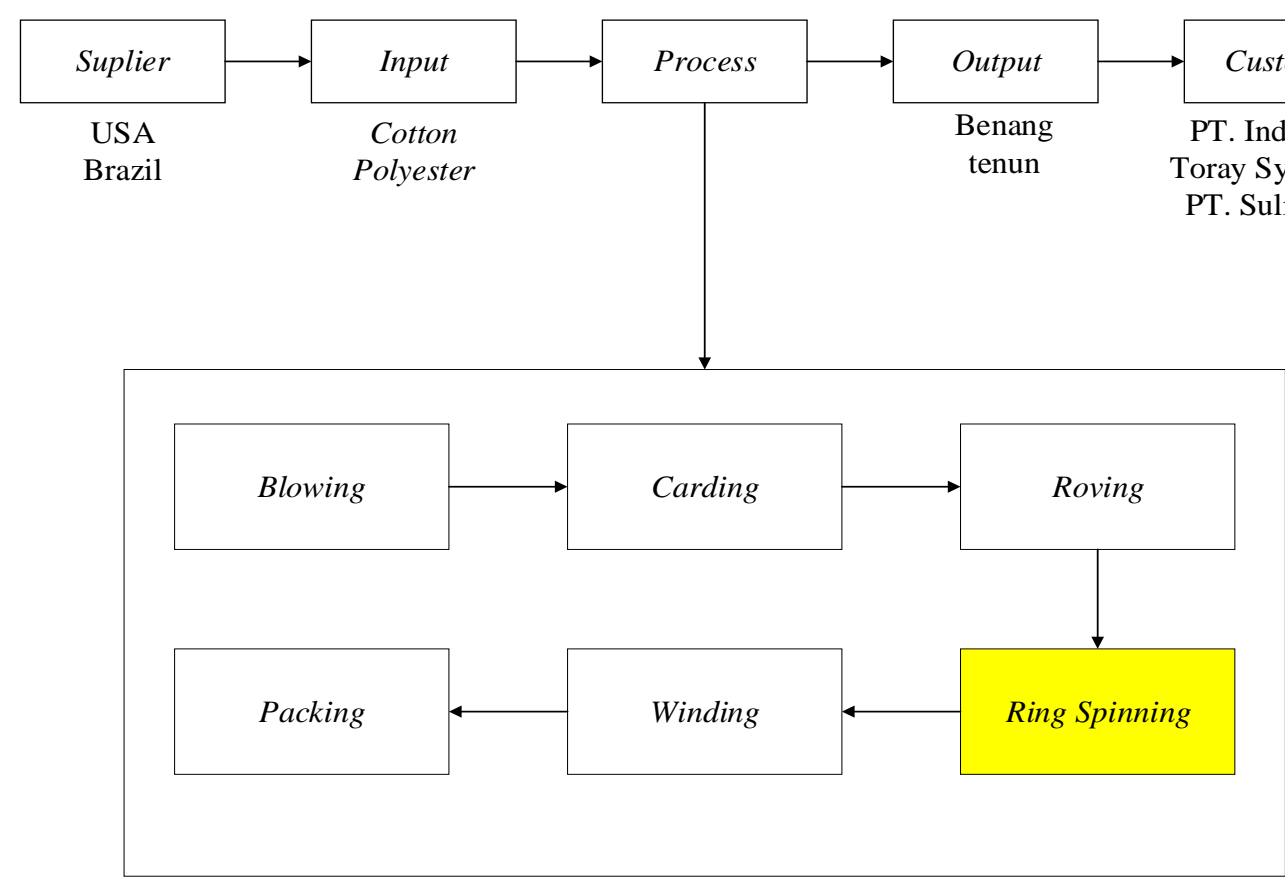

Gambar 1. Diagram SIPOC

\section{Measure}

1. Menentukan Critical To Quality (CTQ)

Penentuan CTQ dilakukan untuk mengidentifikasi karakteristik yang berpotensi menjadi cacat pada produk akhir. Pada penelitian ini diketahui jenis cacat yang terjadi dapat dibagi menjadi lima kategori yaitu kusut, kotor, putus, tebal, tipis.
2. Menentukan DPMO dan Level Sigma

Berdasarkan hasil perhitungan rata-rata nilai DPMO didapat sebesar 17.130 dengan Level sigma sebesar 3,6. Level sigma tersebut sudah melebihi rata-rata industri Indonesia, tetapi dari jumlah produksi selama 12 bulan terdapat persentase cacat sebesar $8,7 \%$, cacat tersebut melebihi target yang telah ditetapkan oleh 
perusahaan yaitu sebesar $5 \%$. Pengendalian kualitas masih tetap diperlukan untuk meningkatkan level sigma dan dapat mencapai target perusahaan sebesar $5 \%$.

3. Analisis Menggunakan Peta Kendali $P$

Peta kendali $p$ mempunyai manfaat untuk membantu pengendalian kualitas produksi serta dapat memberikan informasi mengenai kapan dan dimana perusahaan harus melakukan perbaikan kualitas.

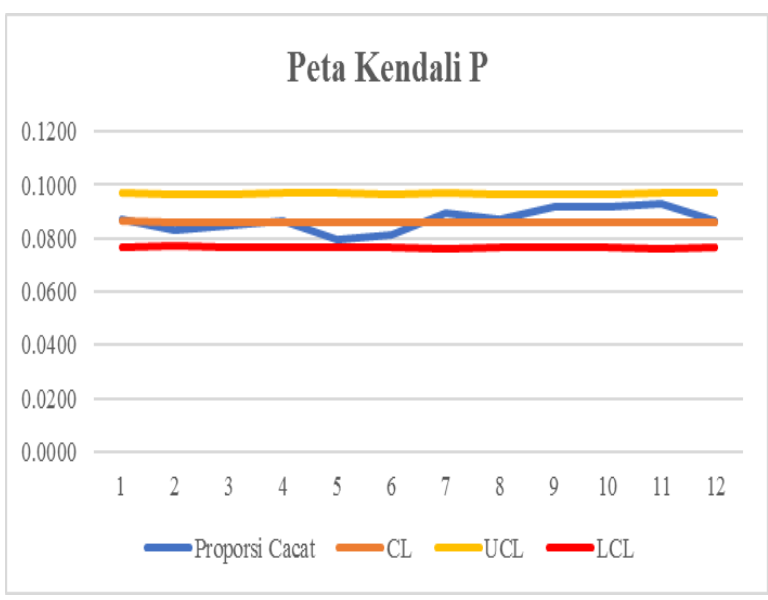

Gambar 2. Peta Kendali P pada bagian spinning

Berdasarkan gambar 2 dapat dilihat bahwa data yang diperoleh seluruhnya berada dalam batas kendali atas maupun batas kendali bawah sehingga bisa dikatakan bahwa proses produksi benang carded pada bulan April 2017 - Maret 2018 terkendali. Meskipun dalam batas kendali, ada beberapa data yang berpotensi melebihi batas kendali bawah dan batas kendali atas yang menjadi suatu indikasi untuk dilakukannya perbaikan pada proses tersebut.

\section{Analyze}

1. Analisa Diagram Pareto

Diagram pareto adalah diagram yang digunakan untuk mengidentifikasi, mengurutkan dan bekerja untuk menyisihkan kerusakan produk cacat.

Dari hasil yang didapatkan jenis cacat dengan persentase terbesar yaitu untuk jenis cacat benang kusut dengan persentase sebesar $53,1 \%$ dan cacat benang kotor sebesar $25,6 \%$. Adapun persentase terkecil ada pada jenis cacat benang putus $11,3 \%$, cacat benang tebal dengan persentase $5,5 \%$ dan persentase cacat benang tipis sebesar $4,5 \%$.

2. Analisis Diagram Sebab Akibat (Cause and Effect Diagram)

Setelah diketahui jenis-jenis cacat yang terjadi, maka perlu mengambil langkah-langkah perbaikan untuk mencegah timbulnya kerusakan yang serupa. Hal penting yang harus dilakukan dan ditelusuri adalah mencari penyebab timbulnya kerusakan tersebut. Sebagai alat bantu untuk mencari penyebab terjadinya cacat tersebut, digunakan diagram sebab akibat atau yang disebut fishbone chart.

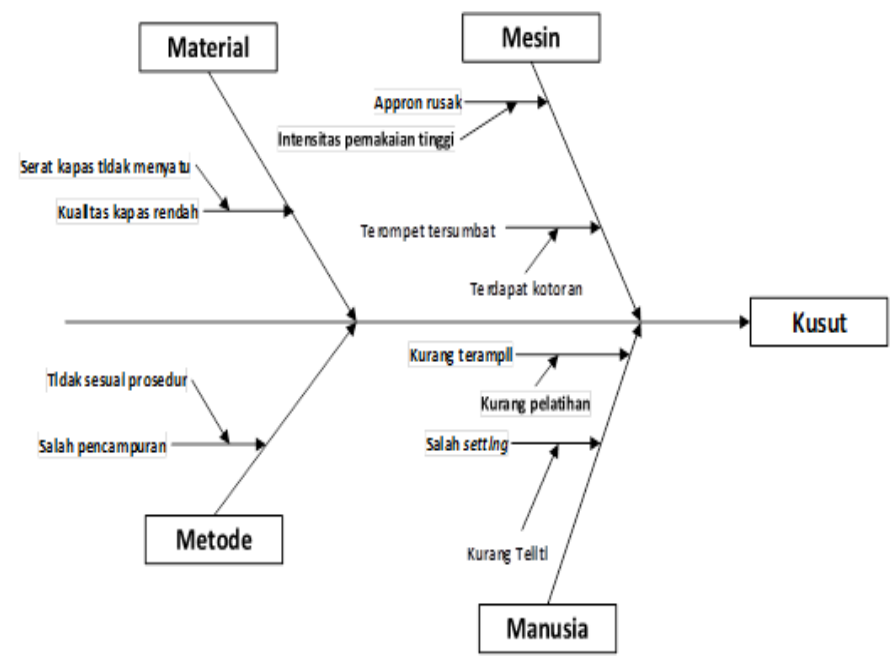

Gambar 3. Diagram Sebab Akibat Jenis Cacat Kusut

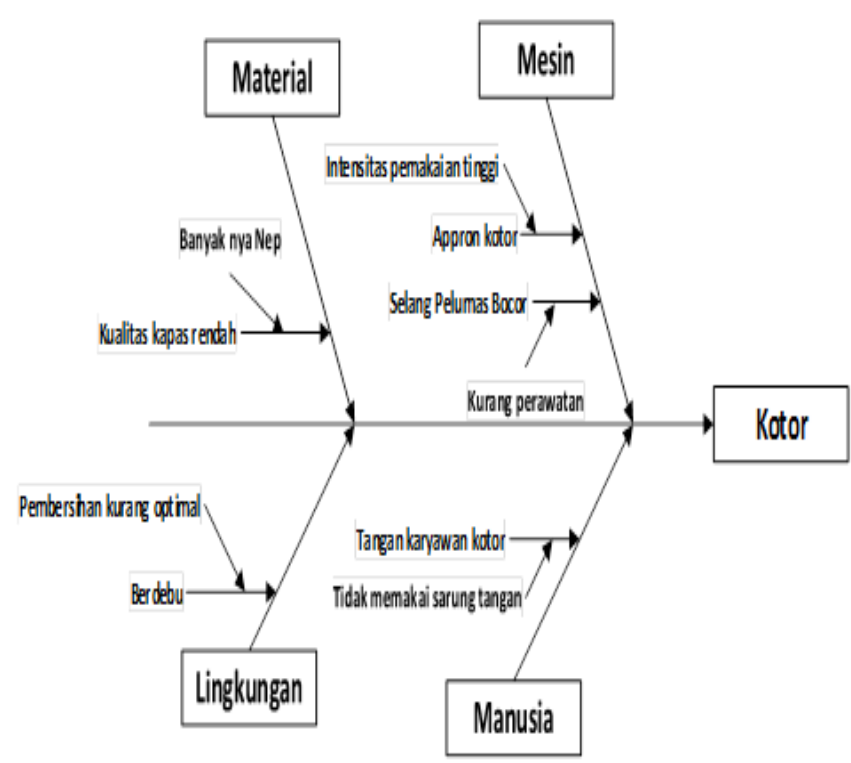

Gambar 4. Diagram Sebab Akibat Jenis Cacat Kotor

\section{Analisis Failure Mode and Effect Analysis (FMEA)}

Berdasarkan Tabel 2. FMEA diperoleh faktor-faktor penyebab kegagalan proses yang mengakibatkan terjadinya cacat. Faktor-faktor dengan nilai Risk priority number (RPN) tertinggi pada cacat kusut yaitu appron rusak dengan nilai RPN 140 dan terompet tersumbat sebesar 120, sedangkan nilai RPN tertinggi pada cacat kotor 
yaitu appron kotor 150 dan selang pelumas bocor perbaikan untuk menurunkan tingkat kecacatan. sebesar 120. Pada tahap selanjutnya dilakukan

Tabel 2. Analisis Failure Mode and Effect Analysis (FMEA)

\begin{tabular}{|c|c|c|c|c|c|c|c|c|c|c|}
\hline No. & $\begin{array}{l}\text { Jenis } \\
\text { Cacat }\end{array}$ & Failur Mode & S & Failur Effect & $\mathrm{O}$ & Cause & $\mathrm{D}$ & RPN & 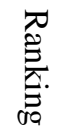 & Control \\
\hline \multirow{6}{*}{1.} & \multirow{6}{*}{ Kusut } & Salah setting. & 5 & $\begin{array}{l}\text { Putaran spindle } \\
\text { tidak sesuai. }\end{array}$ & 4 & Kurang teliti. & 4 & 80 & 3 & $\begin{array}{l}\text { Lakukan } \\
\text { pengawasan. }\end{array}$ \\
\hline & & $\begin{array}{l}\text { Kurang } \\
\text { terampil. }\end{array}$ & 2 & $\begin{array}{l}\text { Tidak mengerti } \\
\text { mesin spinning. }\end{array}$ & 3 & $\begin{array}{l}\text { Kurang } \\
\text { pelatihan. }\end{array}$ & 3 & 18 & 6 & $\begin{array}{l}\text { Lakukan } \\
\text { pelatihan. }\end{array}$ \\
\hline & & $\begin{array}{l}\text { Terompet } \\
\text { tersumbat. }\end{array}$ & 6 & $\begin{array}{l}\text { Benang tidak } \\
\text { masuk } \\
\text { terompet. }\end{array}$ & 4 & $\begin{array}{l}\text { Terdapat } \\
\text { kotoran. }\end{array}$ & 5 & 120 & 2 & $\begin{array}{l}\text { Lakukan } \\
\text { pembersihan. }\end{array}$ \\
\hline & & Appron rusak. & 7 & $\begin{array}{l}\text { Serat benang } \\
\text { tidak menyatu. }\end{array}$ & 5 & $\begin{array}{l}\text { Intensitas } \\
\text { pemakaian } \\
\text { tinggi. }\end{array}$ & 4 & 140 & 1 & $\begin{array}{l}\text { Ganti appron } \\
\text { yang rusak. }\end{array}$ \\
\hline & & $\begin{array}{l}\text { Kualitas kapas } \\
\text { rendah. }\end{array}$ & 2 & Benang rapuh. & 3 & $\begin{array}{l}\text { Serat kapas } \\
\text { tidak menyatu. }\end{array}$ & 4 & 24 & 5 & $\begin{array}{l}\text { Lakukan } \\
\text { pengawasan. }\end{array}$ \\
\hline & & $\begin{array}{l}\text { Salah } \\
\text { pencampuran. }\end{array}$ & 3 & $\begin{array}{l}\text { Benang tidak } \\
\text { menyatu. }\end{array}$ & 3 & $\begin{array}{l}\text { Tidak sesuai } \\
\text { prosedur. }\end{array}$ & 5 & 45 & 4 & $\begin{array}{l}\text { Lakukan } \\
\text { pengecekan. }\end{array}$ \\
\hline \multirow{5}{*}{2.} & \multirow{5}{*}{ Kotor } & $\begin{array}{l}\text { Tangan } \\
\text { karyawan } \\
\text { kotor. }\end{array}$ & 4 & $\begin{array}{l}\text { Benang terkena } \\
\text { kotoran }\end{array}$ & 3 & $\begin{array}{l}\text { Tidak } \\
\text { memakai } \\
\text { sarung tangan. }\end{array}$ & 3 & 36 & 3 & $\begin{array}{l}\text { Memakai } \\
\text { sarung tangan } \\
\text { saat produksi. }\end{array}$ \\
\hline & & $\begin{array}{l}\text { Selang } \\
\text { pelumas bocor. }\end{array}$ & 6 & $\begin{array}{l}\text { Benang terkena } \\
\text { cairan oli. }\end{array}$ & 4 & $\begin{array}{l}\text { Kurang } \\
\text { perawatan. }\end{array}$ & 5 & 120 & 2 & $\begin{array}{l}\text { Lakukan } \\
\text { pengecekan. }\end{array}$ \\
\hline & & Appron kotor. & 6 & $\begin{array}{l}\text { Benang } \\
\text { lengket. }\end{array}$ & 5 & $\begin{array}{l}\text { Intensitas } \\
\text { pemakaian } \\
\text { tinggi. }\end{array}$ & 5 & 150 & 1 & $\begin{array}{l}\text { Lakukan } \\
\text { pembersihan } \\
\text { appron. }\end{array}$ \\
\hline & & $\begin{array}{l}\text { Kualitas kapas } \\
\text { rendah. }\end{array}$ & 2 & $\begin{array}{l}\text { Gempalan serat } \\
\text { menempel pada } \\
\text { benang. }\end{array}$ & 3 & $\begin{array}{l}\text { Banyaknya } \\
\text { Neps. }\end{array}$ & 4 & 24 & 4 & $\begin{array}{l}\text { Lakukan } \\
\text { pemeriksaan } \\
\text { bahan baku. }\end{array}$ \\
\hline & & Berdebu. & 5 & $\begin{array}{l}\text { Benang } \\
\text { berbulu. }\end{array}$ & 2 & $\begin{array}{l}\text { Pembersihan } \\
\text { kurang } \\
\text { optimal. }\end{array}$ & 2 & 20 & 5 & $\begin{array}{l}\text { Lakukan } \\
\text { pemeriksaan. }\end{array}$ \\
\hline
\end{tabular}

\section{Improve}

Improve (tahap perbaikan) merupakan tahapan keempat dalam perbaikan kualitas metode Six sigma. Pada tahapan perbaikan ini diterapkan suatu rencana tindakan peningkatan kualitas Six sigma, melalui perbaikan terhadap sumber-sumber penyebab terjadinya cacat. Rencana perbaikan dilakukan terhadap segala sumber yang memiliki potensi terjadinya cacat berdasarkan hasil analisis Cause and Effect Diagram dan analisis Failure Mode and Effect
Analysis (FMEA) dengan memberikan recana perbaikan berdasarkan nilai prioritas tertinggi dengan menggunakan $5 \mathrm{~W}+1 \mathrm{H}$.

Setelah memberikan usulan perbaikan berdasarkan nilai RPN tertinggi, peneliti kembali memberikan usulan perencanaan perbaikan jangka panjang yang bertujuan untuk mencegah terjadinya cacat serta agar mendapatkan hasil yang sesuai dan mencapai tujuan yang telah ditetapkan dengan menggunakan $5 \mathrm{~W}+1 \mathrm{H}$ dapat dilihat pada tabel 4. 
Tabel 3. Rencana Perbaikan $5 \mathrm{~W}+1 \mathrm{H}$

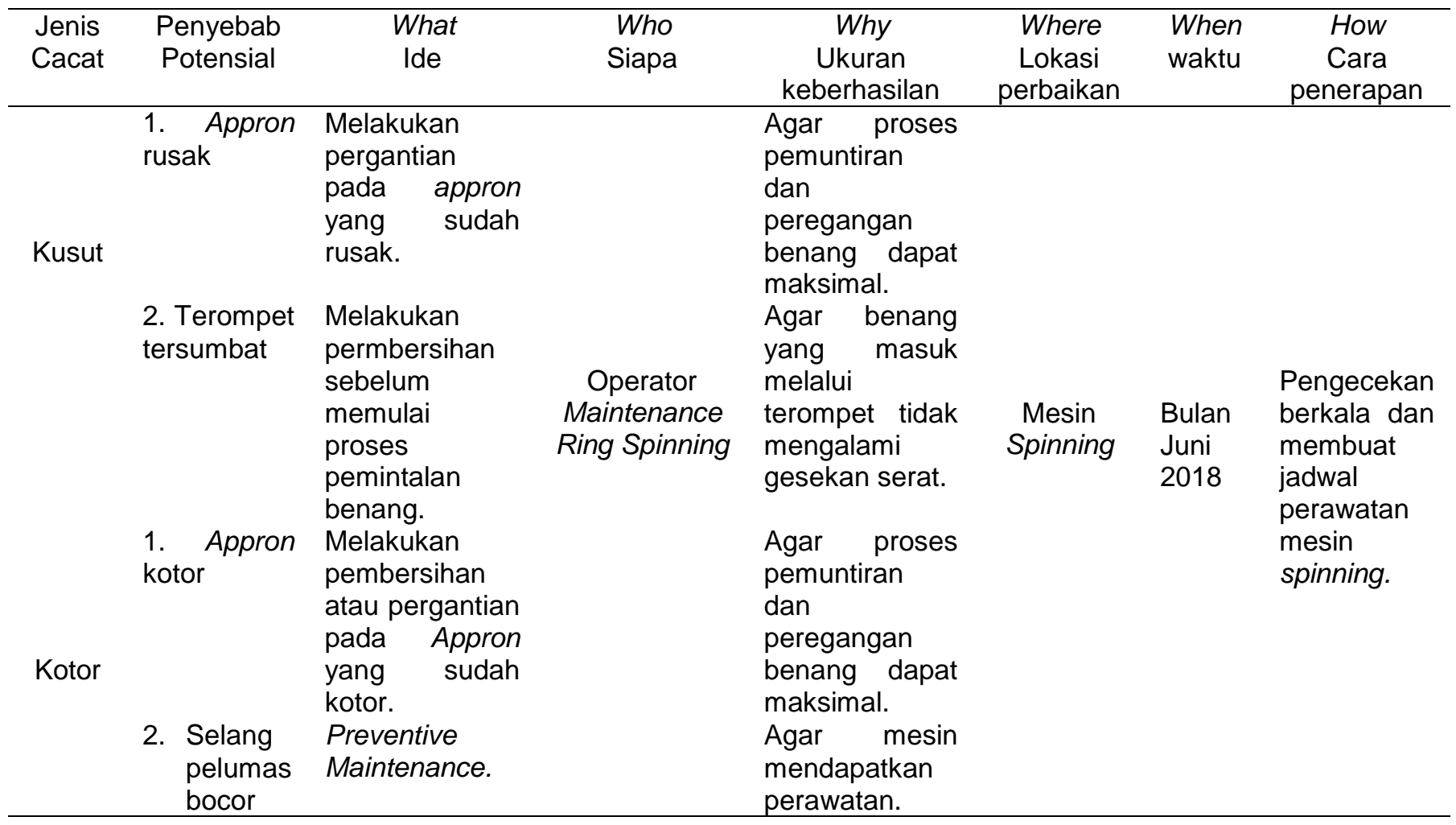

Tabel 4. Rencana Perbaikan Jangka Panjang $5 \mathrm{~W}+1 \mathrm{H}$

\begin{tabular}{|c|c|c|c|c|c|}
\hline $\begin{array}{l}\text { What } \\
\text { Ide }\end{array}$ & $\begin{array}{l}\text { Who } \\
\text { Siapa }\end{array}$ & $\begin{array}{c}\text { Why } \\
\text { Ukuran } \\
\text { keberhasilan }\end{array}$ & $\begin{array}{l}\text { Where } \\
\text { Lokasi } \\
\text { perbaikan }\end{array}$ & $\begin{array}{l}\text { When } \\
\text { waktu }\end{array}$ & $\begin{array}{c}\text { How } \\
\text { Cara penerapan }\end{array}$ \\
\hline $\begin{array}{l}\text { Membentuk } \\
\text { kelompok } \\
\text { kecil atau } \\
\text { biasa di sebut } \\
\text { gugus kendali } \\
\text { mutu (GKM) }\end{array}$ & Karyawan & $\begin{array}{l}\text { Untuk } \\
\text { meningkatkan } \\
\text { keterampilan } \\
\text { karyawa dalam } \\
\text { mengatasi } \\
\text { masalah yang ada } \\
\text { pada bagian } \\
\text { Spinning }\end{array}$ & $\begin{array}{l}\text { Ring } \\
\text { Spinning }\end{array}$ & $\begin{array}{l}\text { Pada saat } \\
\text { proses } \\
\text { produksi } \\
\text { benang. }\end{array}$ & $\begin{array}{l}\text { 1. Mengidentifikasi masalah yang ada. } \\
\text { 2. Penetapan target. } \\
\text { 3. Analisa kondisi yang ada. } \\
\text { 4. Analisa sebab akibat. } \\
\text { 5. Merencanakan perbaikan. } \\
\text { 6. Pelaksanaan perbaikan. } \\
\text { 7. Evaluasi perbaikan. } \\
\text { 8. Membuat standarisasi. }\end{array}$ \\
\hline
\end{tabular}

\section{KESIMPULAN}

Dari hasil penelitian yang telah dilakukan, maka penulis memberikan simpulan bahwa nilai DPMO pada jenis benang CD dibagian spinning sebesar 17.130 dan nilai sigma 3,6. Nilai sigma tersebut sudah melebihi rata-rata industri Indonesia, tetapi dari jumlah produksi selama 12 bulan terdapat persentase cacat sebesar $8,7 \%$, cacat tersebut melebihi target yang telah ditetapkan oleh perusahaan yaitu sebesar 5\%. Appron rusak dan kotor, terompet tersumbat, serta selang pelumas bocor, merupakan faktor yang dominan yang mengakibatkan cacat benang kusut dengan persentase sebesar $53,1 \%$ dan cacat benang kotor sebesar $25,6 \%$. Adapun persentase terkecil ada pada jenis cacat benang putus $11,3 \%$, cacat benang tebal dengan persentase $5,5 \%$ dan persentase cacat benang tipis sebesar $4,5 \%$. Risk priority number (RPN) tertinggi pada cacat kusut yaitu appron rusak dengan nilai RPN sebesar 140 dan terompet tersumbat sebesar 120 , sedangkan nilai RPN tertinggi pada cacat kotor yaitu appron kotor sebesar 150 dan selang pelumas bocor sebesar 120, maka diberikan usulan perencanaan perbaikan jangka panjang yang bertujuan untuk mencegah terjadinya cacat serta agar mendapatkan hasil yang sesuai dan mencapai 
tujuan yang telah ditetapkan dengan menggunakan $5 \mathrm{~W}+1 \mathrm{H}$.

\section{DAFTAR PUSTAKA}

Das, P., Roy, S., \& Antony, J. (2007). An application of six sigma methodology to reduce lot-to-lot shade variation of linen fabrics. Journal of Industrial Textiles, 36(3), 227-251.

Gaspersz, V. (2002). Pedoman implementasi program six sigma terintegrasi dengan ISO 9001: 2000, MBNQA, dan HACCP. Jakarta :PT. Gramedia Pustaka Utama.

Gupta, N., \& Bharti, P. K. (2013). Implementation of Six Sigma for minimizing the defects rate at a yarn manufacturing company. International Journal of Engineering Research and Applications, 3(2), 10001011.

Hussain, T., Jamshaid, H., \& Sohail, A. (2014). Reducing defects in textile weaving by applying Six Sigma methodology: a case study. International Journal of Six Sigma and Competitive Advantage, 8(2), 95-104.

Sirine, H., \& Kurniawati, E. P. (2017). Pengendalian Kualitas Menggunakan Metode Six Sigma (Studi Kasus pada PT Diras Concept Sukoharjo). Asian Journal of Innovation and Entrepreneurship, 2(03), 254-290.

Supriyadi, S., Ramayanti, G., \& Roberto, A. C. (2017). Analisis Kualitas Produk dengan Pendekatan Six Sigma. In Prosiding SNTI dan SATELIT 2017 (pp. D7-13). Malang: Jurusan Teknik Industri Universitas Brawijaya.

Zahara, F. (2014). Pengendalian Kualitas Part Trim Rear Quarter Right Apv Arena Dengan Menggunakan Metode Six Sigma Di PT. Suzuki Indomobil Motor. Optimasi Sistem Industri, 13(1), 486-502. 